\title{
Low-Dose Involved-Field Radiotherapy in Relapsed Low-Grade Non-Hodgkin's Lymphoma in Elderly Patients (Mansoura University Experience)
}

\author{
Hend Ahmed El-Hadaad*, Hanan Ahmed Wahba, Ibrahim Awad \\ Clinical Oncology and Nuclear Medicine, Mansoura University, Mansoura, Egypt \\ Email: ${ }^{*}$ hend am@mans.edu.eg
}

Received 17 March 2014; revised 15 April 2014; accepted 22 April 2014

Copyright (C) 2014 by authors and Scientific Research Publishing Inc.

This work is licensed under the Creative Commons Attribution International License (CC BY). http://creativecommons.org/licenses/by/4.0/

(c) (i) Open Access

\begin{abstract}
Purpose: To assess the response rate, duration of response and prognostic factors affecting response after low-dose involved-field radiotherapy in patients with relapsed low-grade B-cell nonHodgkin lymphoma. Patients and Methods: Forty-four patients were included. Patients were treated with a total dose of $4 \mathrm{~Gy}(2 \times 2 \mathrm{~Gy})$ using $6-15 \mathrm{Mv}$ photon or electron beam. Results: most patients were above age of 60 years $(59 \%)$ with male predominance. Follicular lymphoma was the most common pathological type; bulky disease $(>5 \mathrm{~cm})$ was presented in $61.4 \%$. Patients who received only 2 regimens were $63.7 \%$ and $31.8 \%$ had $>2$ involved sites. No treatment related toxicity was observed. The overall response rate was $88.7 \%$; complete response was reached in $59.1 \%$ and stable disease in $6.8 \%$, progressive disease in $4.5 \%$. Median time to local progression was 33 months (95\% CI 23.70 - 42.29); 2-year local progression free survival was $78 \%$. Response rate was found to be dependent on age, number of involved sites and lymph node size but independent on sex, pathological type, number of prior regimens, LDH level and time since diagnosis. Conclusion: Short-course-low dose palliative radiotherapy $(2 \times 2 \mathrm{~Gy})$ affords an attractive option for treatment of relapsed low-grade non-Hodgkin's lymphoma due to high response rates. However, these results had to be confirmed in a larger number of patients.
\end{abstract}

\section{Keywords}

Low-Grade Lymphoma, Relapsed Non-Hodgkin's Lymphoma, Low-Dose Radiotherapy in Lymphoma

\footnotetext{
"Corresponding author.
}

How to cite this paper: El-Hadaad, H.A., et al. (2014) Low-Dose Involved-Field Radiotherapy in Relapsed Low-Grade Non-Hodgkin's Lymphoma in Elderly Patients (Mansoura University Experience). Journal of Cancer Therapy, 5, 500-505. 


\section{Introduction}

Of all indolent non-Hodgkin lymphoma (NHL), 80\% of patients present with advanced Ann Arbor stage III or IV and incidence rises with age [1]. Although generally not curable with conventional therapy, patients with indolent lymphoma have a relatively long life expectancy. The natural history of indolent lymphoma is characterized by multiple relapses and the intervals between subsequent relapses tend to be shortening over time [2].

Chemotherapy and immunotherapy can be effective in achieving repeated remissions [3] [4]. However, systemic therapy can be associated with significant toxicity especially in older patients with comorbid illness. The disease can also eventually become refractory to systemic therapy. Given the radiosensitivity of indolent lymphoma, local radiation therapy plays an important role in palliation of these patients in the case of symptomatic disease due to progression, compression of a vital organ by a bulky mass or cytopenia [5]. Conventional-dose radiation therapy can have considerable side effects affecting patient's quality of life and ability to receive further systemic therapy.

The objective of this prospective study was to assess the response rate, duration of response, and prognostic factors affecting response after low-dose involved-field radiotherapy (LD-IF-RT) in patients with relapsed lowgrade B-cell NHL.

\section{Patients and Method}

The institutional Review Board approved this study protocol and all patients were required to provide written informed consent.

Between June 2005 and December 2010, a total of 44 patients were included, they had symptomatic relapsed B-cell indolent lymphoma that was proven histologically since no more than 1 year. Before and after irradiation, all patients were assessed by physical examination, ultrasound, bone marrow biopsy, computed tomography.

Treatment consisted of a total dose of 4 Gy delivered in two fractions over 2 consecutive days. No other therapy was given concomitantly with irradiation. Megavoltage photons from 6-15 MV or electron beams were used. The target area included the involved site or the affected lymph node with a 2-cm margin. If patients were irradiated at more than one site and the response differed for each site (e.g. complete response in one site and partial response in another) the disease was assigned to the worst category.

Response was determined clinically or radiologically according to the Response Evaluation Criteria in Solid tumors criteria [6]. The first evaluation was performed 1 month after the end of treatment then every 3 months for first year then every 6 months for 2 years then annually thereafter. A complete response (CR) was defined as a complete disappearance of clinically or radiologically detectable disease within the treatment field; a partial response (PR), as a decrease of at least $30 \%$ in the sum of diameters of target lesions. Stable disease (SD) was defined as neither sufficient shrinkage to qualify for PR non sufficient increase to qualify for progressive disease (PD). Patients with PD (with at least 20\% increase in the sum of diameters of the target lesions) were considered as non responders as well as those with SD.

Toxicity was scored according to the toxicity scale of the National Cancer Institute Common Terminology Criteria for Adverse Events v.3.0 [7]. Patients with bulky diseases received antihyperuricemic medication (allopurinol); dosage depending on renal function.

The main end points of the study were in-field lymphoma control and progression free survival.

Statistical analysis: The data were encoded in a computer using the Statistical Package for Social Sciences (SPSS) version 15.0 (Chicago, IL, USA). Distributions of survival functions were estimated using the KaplanMeier method. Non-normally distributed data was expressed as number and percentage. Chi square was used as a test of significance. $P$ values of $<0.05$ was considered significant.

\section{Results}

Table 1 shows the characteristics of 44 eligible patients entered the study. There were male predominance; most patients were above age of 60 years. Follicular lymphoma was the most common pathological type, $63.7 \%$ of patients received only 2 regimens of treatment (radiotherapy and chemotherapy). Lymph node size of $>5 \mathrm{~cm}$ was observed in $61.4 \%$ while $68.2 \%$ of patients had 1 - 2 involved sites. High lactate dehydrogenase level was recorded in $70.4 \%$. Time since diagnosis was 25 - 60 months in $34 \%$.

Response rate was $88.7 \%$ with complete response (CR) in $59.1 \%$ and partial response (PR) in $29.6 \%$. Stable 
Table 1. Patients characteristics $(n=44)$.

\begin{tabular}{|c|c|c|}
\hline Characteristic & $\mathbf{N}$ & $\%$ \\
\hline \multicolumn{3}{|l|}{ Sex: } \\
\hline Male & 24 & 54.5 \\
\hline Female & 20 & 45.5 \\
\hline \multicolumn{3}{|l|}{ Age: median 57 years } \\
\hline$\leq 60 \mathrm{Y}$ & 18 & 40.9 \\
\hline$>60 \mathrm{Y}$ & 26 & 59.1 \\
\hline \multicolumn{3}{|l|}{ Pathology } \\
\hline CLL/SLL & 2 & 4.5 \\
\hline \multicolumn{3}{|l|}{ Follicular lymphoma } \\
\hline Grade 1 & 22 & 50 \\
\hline Grade 2 & 18 & 41 \\
\hline MALT & 2 & 4.5 \\
\hline \multicolumn{3}{|c|}{ Number of prior regimens } \\
\hline $0-2$ & 28 & 63.7 \\
\hline $3-5$ & 16 & 36.3 \\
\hline \multicolumn{3}{|c|}{ Number of involved sites } \\
\hline $1-2$ & 30 & 68.2 \\
\hline $3-5$ & 14 & 31.8 \\
\hline \multicolumn{3}{|c|}{ Size of the largest lymph node } \\
\hline$\leq 5 \mathrm{~cm}$ & 17 & 38.6 \\
\hline$>5 \mathrm{~cm}$ & 27 & 61.4 \\
\hline \multicolumn{3}{|l|}{ LDH } \\
\hline High & 31 & 70.4 \\
\hline Normal & 13 & 29.6 \\
\hline \multicolumn{3}{|c|}{ Time since diagnosis, median $=42$ months } \\
\hline$\leq 24$ months & 12 & 27.3 \\
\hline 25 - 60 months & 15 & 34.1 \\
\hline 61 - 120 months & 10 & 22.7 \\
\hline$\geq 120$ months & 7 & 15.9 \\
\hline
\end{tabular}

disease (SD) was reported in $6.8 \%$ and progressive disease (PD) in $4.5 \%$ (Table 2).

Frequently, patients noticed a response within 2 weeks of treatment. All patients fulfilled the protocol radiotherapy prescriptions.

Multivariate analysis was performed to determine which factors were predictive of response rate (Table 3 ) Younger age $(<60 \mathrm{y})$, less number of involved sites $(\leq 2)$ and smaller size $(<5 \mathrm{~cm})$ of involved lymph node (LN) had statistically significant impact on response rate $(\mathrm{P}=0.04,0.01,0.04$ respectively). Other prognostic factors for response rate (i.e., sex, pathological type, number of prior regimens, LDH level and time since diagnosis) were not found to be related to response rate (RR). No treatment related toxicity was observed. Four patients died during follow-up period due to causes unrelated to cancer.

After median follow-up of 37 months, 2-year local progression free survival (PFS) was 78\% (Figure 1) with median time to local progression 33months (95\% CI: 23.70 - 42.29).

\section{Discussion}

Watchful waiting is a widely accepted approach, both at diagnosis and in recurrent and advanced-stage asymp- 
Table 2. Response rate.

\begin{tabular}{ccc}
\hline Response & N & \% \\
\hline Complete response (CR) & 26 & 59.1 \\
Partial response (PR) & 13 & 29.6 \\
Stable disease (SD) & 3 & 6.8 \\
Progressive disease (PD) & 2 & 4.5 \\
\hline
\end{tabular}

Table 3. Multivariate analysis of prognostic factors affecting response rate.

\begin{tabular}{|c|c|c|}
\hline Factors & Response rate & $\mathbf{P}$ \\
\hline \multicolumn{3}{|l|}{ Sex } \\
\hline Male & $21 / 24(87.5 \%)$ & \multirow[t]{2}{*}{0.80} \\
\hline female & $17 / 20$ (85\%) & \\
\hline \multicolumn{3}{|l|}{ Age } \\
\hline$\leq 60 \mathrm{y}$ & 17/18 (94.4\%) & \multirow[t]{2}{*}{0.04} \\
\hline$>60 \mathrm{y}$ & 18/26 (69.2\%) & \\
\hline \multicolumn{3}{|l|}{ Pathology } \\
\hline CLL/SLL & $2 / 2(100 \%)$ & \multirow{5}{*}{0.90} \\
\hline Folicullar lymp & & \\
\hline Grade1 & 21/22 (95.5\%) & \\
\hline Grade2 & 17/18 (94.4\%) & \\
\hline MALT & $2 / 2(100 \%)$ & \\
\hline \multicolumn{3}{|c|}{ Number of prior regimens } \\
\hline $0-2$ & 25/28 (89.2\%) & \multirow[t]{2}{*}{0.85} \\
\hline $3-5$ & $14 / 16(87.5 \%)$ & \\
\hline \multicolumn{3}{|c|}{ Number of involved sites } \\
\hline $1-2$ & 28/30 (26.2\%) & \multirow[t]{2}{*}{0.01} \\
\hline $3-5$ & 9/14 (64.3\%) & \\
\hline \multicolumn{3}{|c|}{ Size of the largest LN } \\
\hline$\leq 5 \mathrm{~cm}$ & 15/17 (88.3\%) & \multirow[t]{2}{*}{0.04} \\
\hline$>5 \mathrm{~cm}$ & $16 / 27$ (59.3\%) & \\
\hline \multicolumn{3}{|l|}{ LDH } \\
\hline High & 29/31 (93.5\%) & \multirow[t]{2}{*}{0.88} \\
\hline Normal & 12/13 (92.3\%) & \\
\hline \multicolumn{3}{|c|}{ Time since diagnosis } \\
\hline$\leq 24 \mathrm{~m}$ & 10/12 (83.3\%) & \multirow{4}{*}{0.98} \\
\hline $25-60 m$ & $12 / 15$ (80\%) & \\
\hline $61-120 m$ & 8/10 (80\%) & \\
\hline$\geq 120 \mathrm{~m}$ & 6/7 (85.7\%) & \\
\hline
\end{tabular}

tomatic patients. However, in the case of symptomatic disease, a regimen should be chosen that provides high response rates with a rapid onset of response of short treatment duration and leaves patients with a minimum toxicity.

This study of LD-IF-RT using 4 Gy in two fractions in 44 patients with relapsed indolent B-cell NHL shows an overall response rate of $88.7 \%$ with a CR achieved in $59 \%$ of patients.

Responses were often rapid and treatment-related toxicity was effectively absent. These results compare fa- 


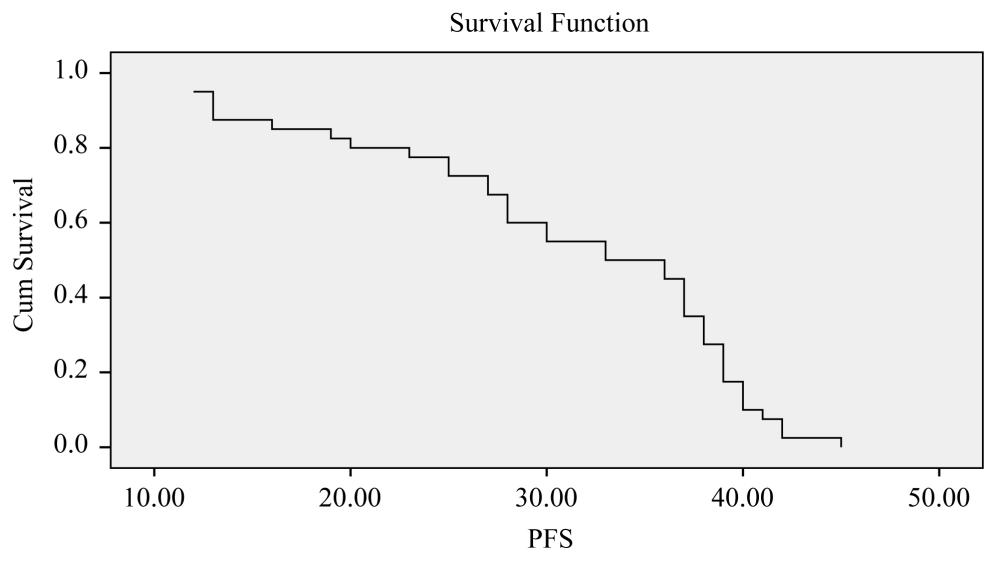

Figure 1. Progression-free survival.

vorably with others [8]-[11].

Regarding the prognostic factors, patients younger than 60 years, those with only one or two lymphoma sites and disease size $\leq 5 \mathrm{~cm}$ had significantly higher RR. These results are in agreement with that reported by Rossier et al. [12], Chan et al. [13] and Girinsky et al. [8]. Sex, pathological type, number of prior regimens, LDH level and time since diagnosis did not significantly predict response rates.

Johannsson et al. [9] found that patients with chronic lymphocytic leukemia/small lymphocytic lymphoma (CLL/SLL) had lower RR compared with patients with follicular lymphoma.

Our study, however, predominantly consisted of patients with follicular lymphoma (91\%), rendering analysis by pathological type difficult.

Additional data are needed on the effectiveness of palliative LD-IF-RT on different subtypes of NHL. Rossier et al. [12] reported that previous chemotherapy was one of the worse prognostic factors regarding the benefit of such irradiation that not found in our study.

The 2-year PFS was 78\% that comparable to results in other series reporting PFS rate of $76 \%$ - 92\% [8] [10] [14].

In general, cancer patients experience many problems that have a negative influence on their quality of life. These problems can be caused both by the disease itself, but also by treatment side effects. Webster and Cella [15] showed that 141 lymphoma patients had significantly lower physical, emotional and functional well-being as well as lower total quality-of-life scores after treatment as compared with base line values. As far as quality of life is concerned, they advise treating these patients with the least aggressive approach possible. The lack of toxicity and the non aggressive nature of this LD-IF-RT regimen may contribute to improve the quality of life of these patients.

\section{Conclusion}

Short-course-low dose palliative radiotherapy ( $2 \times 2 \mathrm{~Gy})$ affords an attractive option for treatment of relapsed low-grade non-Hodgkin's lymphoma due to high response rates. However, the results had been confirmed in a larger number of patients.

\section{References}

[1] Jemal, A., Siegel, R., Ward, E., et al. (2008) Cancer Statistics, 2008. Cancer Journal for Clinicians, 58, 71-96. http://dx.doi.org/10.3322/CA.2007.0010

[2] Mendenhall, N.P. and Lynch, W. (1995) The Low-Grade Lymphomas. Seminars in Radiation Oncology, 5, $254-266$. http://dx.doi.org/10.1016/S1053-4296(05)80025-6

[3] Hiddemann, W., Kneba, M., Dreyling, M., et al. (2005) Front Line Therapy with Rituximab Added to the Combination of Cyclophosphamide, Doxorubicin, Vincristine and Prednisone (CHOP) Significantly Improves the Outcome for Patients with Advanced-Stage Follicular Lymphoma Compared with Therapy with CHOP Alone: Results of a Prospective Randomized Study of the German Low-Grade Lymphoma Study Group. Blood, 106, 3725-3732.

http://dx.doi.org/10.1182/blood-2005-01-0016 
[4] Marcus, R., Imrie, K., Belch, A., et al. (2005) CVP Chemotherapy plus Rituximab Compared with CVP as First-Line Treatment for Advanced Follicular Lymphoma. Blood, 105, 1417-1423. http://dx.doi.org/10.1182/blood-2004-08-3175

[5] Haas, R.L., de Jong, D., Valdes Olmo, S.R.A., et al. (2004) In Vivo Imaging of Radiation Induced Apoptosis in Follicular Lymphoma Patients. International Journal of Radiation Oncology*Biology*Physics, 59, 782-787. http://dx.doi.org/10.1016/j.ijrobp.2003.11.017

[6] Eisenhaurer, E.A., Therasse, P., Bogaerts, J., et al. (2009) New Response Evaluation Criteria in Solid Tumours: Revised RECIST Guideline (Version 1.1). European Journal of Cancer, 45, 228-247. http://dx.doi.org/10.1016/j.ejca.2008.10.026

[7] (2003) Common Terminology Criteria for Adverse Events (CTCAE) v3.0. Seminars in Radiation Oncology, 3, 176-181.

[8] Girinsky, T., Guillot-Vals, D., Koscielny, S., et al. (2001) A High and Sustained Response Rate in Refractory or Relapsing Low-Grade Lymphoma Masses after Low-Dose Radiation: Analysis of Predictive Parameters of Response to Treatment. International Journal of Radiation Oncology*Biology*Physics, 51, 148-155. http://dx.doi.org/10.1016/S0360-3016(01)01626-1

[9] Johannsson, J., Specht, L., Mejer, J., et al. (2002) Phase II Study of Palliative Low-Dose Local Radiotherapy in Disseminated Indolent Non-Hodgiken Lymphoma and Chronic Lymphocytic Leukemia. International Journal of Radiation Oncology*Biology*Physics, 54, 1466-1470. http://dx.doi.org/10.1016/S0360-3016(02)03050-X

[10] Haas, R.L., Poortmans, P., de Jong, D., et al. (2003) High Response Rates and Lasting Remissions after Low-Dose Involved Field Radiotherapy in Indolent Lymphomas. Journal of Clinical Oncology, 21, 2474-2480. http://dx.doi.org/10.1200/JCO.2003.09.542

[11] Ng, M., Wirth, A., Ryan, G., et al. (2006) Value of Low-Dose $2 \times 2$ Gy Palliative Radiotherapy in Advanced LowGrade Non-Hodgkin's Lymphoma. Australasian Radiology, 50, 222-227. http://dx.doi.org/10.1111/j.1440-1673.2006.01566.x

[12] Rossier, C., Schick, U., Miralbell, R., et al. (2011) Low-Dose Radiotherapy in Indolent Lymphoma. International Journal of Radiation Oncology*Biology*Physics, 81, e 1-6.

[13] Chan, E.K., Fung, S., Gospodarowicz, M., et al. (2010) Low Dose Radiation Treatment of Lymphoma Tumors. International Journal of Radiation Oncology*Biology*Physics, 81, e781-786. http://www.ncbi.nlm.nih.gov/pubmed/21167657

[14] Luthy, S.K., Ng, A.K., Silver, B., et al. (2008) Response to Low-Dose Involved-Field Radiotherapy in Patients with Non-Hodgkin's Lymphoma. Annals of Oncology, 19, 2043-2047. http://dx.doi.org/10.1093/annonc/mdn529

[15] Webster, K. and Cella, D. (1998) Quality of Life in Patients with Low-Grade non-Hodgkin's Lymphoma. Oncology, 12, 697-714. 